\title{
THEORETICAL STUDY OF RELIEF VENTING OF DUST EXPLOSION
}

\author{
SHIN-ICHIRO NOMURA AND TATSUO TANAKA \\ Department of Chemical Process Engineering, \\ Hokkaido University, Sapporo 060
}

\begin{abstract}
Relief venting is one of the protective methods most commonly provided against dust explosion hazards. Safety design has so far been based upon the empirical vent ratio, $S / V$, the area of vent per unit volume of vessel. However, direct use of this term as a scale-up factor is not theoretically sound. A revised form of scale-up factor as to relief venting is proposed on the basis of the unsteady-state macroscopic energy balance and several assumptions. The derived results show that the relationship between vent area and vessel volume can be characterized by a dimensionless term which must be used instead of the conventional vent ratio. Calculated results based upon the theory agree fairly well with past experimental data.
\end{abstract}

\section{Introduction}

Powder handling processes are always exposed to the risk of dust explosions, particularly where they involve combustible powders such as coal, grain, metal and plastic. In these processes, therefore, it is necessary to provide a protective installation in order to limit damage by dust explosions. The relief venting method is commonly adopted to reduce the pressure loading exerted on the enclosure to a safe level. Venting area is of controlling importance in determining the maximum explosion pressure in the plant. In other words, the determination of venting area has to be made according to the maximum safe pressure which the plant can withstand.

Although numerous investigations have been reported, no satisfactory basis for designing relief venting has been published, because of lack of theoretical background. At the present stage, venting has been characterized empirically in terms of the vent ratio, i.e., the area of vent per unit volume of the equipment, and most of the data obtained in vented explosions have been plotted against the vent ratio. However, it has been pointed out ${ }^{9}$ that this empirical characterization includes doubt about its validity if it be applied as scale-up factor to plants of different size.

Based on the hydrodynamic theory of the discharge of gases from a high-pressure reservoir, Palmer ${ }^{6}$ and Heinrich ${ }^{4,5)}$ studied vented explosions theoretically by introducing the maximum rate of pressure rise in a closed vessel. But their derived results were insufficient for the description of scale-up effect of the vent area because there was no reliable consideration of

Received October 23, 1979. Correspondence concerning this article should be addressed to $\mathrm{S}$. Nomura. the relationship between maximum rate of pressure rise in a closed vessel and vessel volume.

On the other hand, the authors ${ }^{7}$ derived the theoretical relationship between the two factors mentioned above on the basis of a simple dust cloud model. The result showed that the scale-up empirical relationship called "cubical-law" between maximum rate of pressure rise and vessel volume, $V_{0}$, is valid not only for a spherical vessel but also for a non-spherical one which can conveniently be regarded as a cylinder, that is,

$$
V_{0}^{1 / 3} \cdot \frac{d P}{d t}-\left.\right|_{\max }=K_{q}
$$

where $K_{G}$ is a constant depending upon the dust material, the dust cloud concentration and the average particle size. $K_{G}$ for cylindrical vessels further depends upon the configuration factor specific to the vessel's shape.

This paper deals with the theoretical evaluation of the vent area in vented explosions based on the above relationship of Eq. (1) and the unsteady-state macroscopic energy balance. New information is obtained which shows that the scale-up relationship between the vent area and vessel volume must be a dimensionless factor rather than the vent ratio. The calculated values are confirmed with past experimental data reported by various investigators.

\section{Theoretical Derivations}

A dust explosion can be regarded as a rapid combustion of dust particles suspended in air through a propagation mechanism. In the process of dust combustion, the equation of reaction shows an increase in mole numbers of the resultant gases and the evolution of heat which causes a temperature rise in sur- 


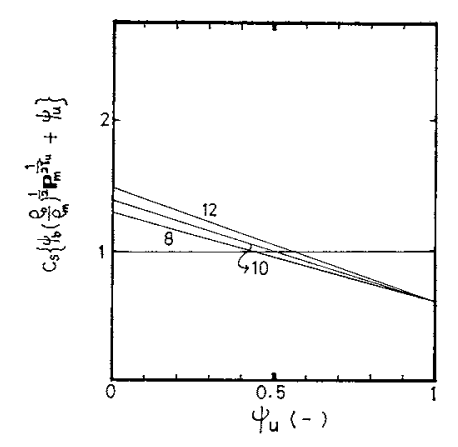

Fig. 1 Calculated values of $C_{s}\left\{\phi_{b}\left(\rho_{0} / \rho_{m}\right)^{1 / 2} P^{1 / 2} \gamma u\right.$ $\left.+\boldsymbol{\phi}_{u}\right\}$ vs. $\boldsymbol{\phi}_{u}$

rounding gases. When a dust explosion occurs in a closed vessel, the pressure in the vessel therefore begins to rise for the above reason. Based on the ideal gas law, the rate of pressure rise under adiabatic conditions has been derived approximately as follows ${ }^{7)}$ :

$$
\begin{aligned}
& \frac{d \boldsymbol{P}}{d t}=\gamma_{u} \cdot \boldsymbol{P}^{1-\left\{1 / \gamma_{u}\right\rangle} \cdot\left(\boldsymbol{P}_{m}{ }^{1 / \gamma_{u}}-1\right) \cdot \frac{d \boldsymbol{M}(t)}{d t} \\
& \boldsymbol{P}=P / P_{0}, \quad \boldsymbol{P}_{m}=P_{\max } / P_{0}, \quad \boldsymbol{M}(t)=M(t) / M_{0}
\end{aligned}
$$

where $P$ is the pressure in the vessel at time $t, P_{0}$, the initial pressure, $P_{\max }$, the maximum pressure, $M(t)$, the mass of particles burnt at time $t, M_{0}$, the maximal mass of particles burnt in the vessel and $\gamma_{u}$, the ratio of specific heats of air.

Next, as to the vented explosion, denoting the area of relief venting as $S$, the macroscopic energy balance gives the following approximate equation of the rate of pressure rise in a vented vessel (see Appendix A):

$$
\begin{aligned}
\frac{d \boldsymbol{P}}{d t}= & \gamma_{u} \cdot \boldsymbol{P}^{1-\left(1 / \gamma_{u}\right)}\left(\boldsymbol{P}_{m}^{1 / \gamma u}-1\right) \frac{d \boldsymbol{M}(t)}{d t} \\
& -\gamma_{u} \boldsymbol{P}^{1-\left(1 / \gamma_{u}\right)} \cdot\left(\boldsymbol{P}_{m}^{1 / \gamma_{u}} \cdot \frac{w_{b}}{\rho_{m} V_{0}}+\frac{w_{u}}{\rho_{0} V_{0}}\right)
\end{aligned}
$$

where the first term of the right-hand side contributes to the pressure rise due to the combustion of particles and has the same form as the right-hand side of Eq. (2). The second term represents the reduction effect of the pressure by discharging the gas through the vent, where $\rho_{m}$ is the density of gas mixtures when $P=P_{\mathrm{max}}$, $\rho_{0}$, the air density at $P=P_{0}$ and $w$, the mass flow rate of gas through the vent where the subscripts $b$ and $u$ denote the burnt gas mixtures and the unburnt air respectively. $w$, in the adiabatic condition, can be given as follows: when

$\boldsymbol{P}<1 / 0.53$,

$$
w=C_{S} \cdot S \cdot\left\{\left(\frac{2 \gamma_{u}}{\gamma_{u}-1}\right) g_{c} \cdot P \cdot \rho\left(\boldsymbol{P}^{-2 / \gamma_{u}}-\boldsymbol{P}^{-\left(\gamma_{u}+1\right) / \gamma_{u}}\right)\right\}^{1 / 2}
$$

and when $\quad \boldsymbol{P}>1 / 0.53$,

$$
w=C_{S} \cdot S \cdot\left\{\gamma_{u} \cdot\left(\frac{2}{\gamma_{u}+1}\right)^{\gamma_{u}+1 / \gamma_{u}-1} \cdot g_{c} \cdot P \cdot \rho\right\}^{1 / 2}
$$

where $C_{S}$ is the discharge coefficient that is $0.6^{1,9)}, S$, the vent area, $\rho$, the gas density and $g_{c}$, the gravitational conversion factor.

Then, denoting the maximum pressure reached in a vented explosion as $P_{v}$, the right-hand side of Eq. (3) becomes zero when $P=P_{v}$. Furthermore, from the necessity of safe design, the most dangerous case has to be considered in Eq. (3). This consideration would permit the introduction of the following assumption: the first term of Eq. (3) could be replaced by the maximum rate of pressure rise in a closed vessel as shown in Eq. (1) because this term in Eq. (3) is of the same type as that in Eq. (2), the rate of pressure rise in a closed vessel. Equation (3) is therefore reduced to

$$
0=\left.\frac{d \boldsymbol{P}}{d t}\right|_{\max }-\gamma_{u} \boldsymbol{P}_{v}^{1-\left\{1 / \gamma_{u}\right)} \cdot\left(\boldsymbol{P}_{m}^{1 / \gamma_{u}} \cdot \frac{w_{b}}{\rho_{m} \cdot V_{0}}+\frac{w_{u}}{\rho_{0} V_{0}}\right)
$$

where $\boldsymbol{P}_{v}=\boldsymbol{P}_{v} / \boldsymbol{P}_{0}$. Denoting the fraction of the total vent area through which the burnt and the unburnt gases are flowing out as $\phi_{b}$ and $\phi_{u}$ respectively, substitution of Eqs. (4) and (5) in Eq. (6) gives the following equations:

$$
\begin{aligned}
\left.\frac{d \boldsymbol{P}}{d t}\right|_{\max }= & \frac{S}{V_{0}}\left(\frac{g_{0} \cdot P_{0}}{\rho_{0}}\right)^{1 / 2} \cdot f\left(\gamma_{u}\right) \cdot g\left(\boldsymbol{P}_{v}\right) \\
& \times\left[C_{S}\left\{\phi_{b} \cdot\left(\frac{\rho_{0}}{\rho_{m}}\right)^{1 / 2} \cdot \boldsymbol{P}_{m}^{1 / 2 \gamma_{u}}+\phi_{u}\right\}\right]
\end{aligned}
$$

where $\phi_{b}+\phi_{u}=1$. As to $f\left(\gamma_{u}\right)$ and $g\left(\boldsymbol{P}_{v}\right)$ in Eq. (7), the two different types of equations must be considered, that is, when $\boldsymbol{P}_{v}<1 / 0.53$,

$$
\begin{aligned}
& f\left(\gamma_{u}\right)=\gamma_{u} \cdot\left(\frac{2 \gamma_{u}}{\gamma_{u}-1}\right)^{1 / 2} \\
& g\left(\boldsymbol{P}_{v}\right)=\boldsymbol{P}_{v}^{1-\left(1 / \gamma_{u}\right)} \cdot\left(\boldsymbol{P}_{v}{ }^{1-\left\{1 / \gamma_{u}\right)}-1\right)^{1 / 2}
\end{aligned}
$$

and when $\boldsymbol{P}_{v}>1 / 0.53$,

$$
\begin{aligned}
& f\left(\gamma_{u}\right)=\gamma_{u} \cdot\left\{\gamma_{u} \cdot\left(\frac{2}{\gamma_{u}+1}\right)^{\gamma_{u}+1 / \gamma_{u}-1}\right\}^{1 / 2} \\
& g\left(\boldsymbol{P}_{v}\right)=\boldsymbol{P}_{v}\left(3 \gamma_{u}-1\right) / 2 \gamma_{u}
\end{aligned}
$$

Hence, the effect of vessel volume on vent area can be represented by substitution of Eq. (1) in Eq. (7) as follows:

$$
\begin{aligned}
\left(\frac{S}{V_{0}^{2 / 3}}\right)^{-1}= & \frac{P_{0}}{K_{G}}\left(\frac{g_{c} \cdot P_{0}}{\rho_{0}}\right)^{1 / 2} \cdot f\left(\gamma_{u}\right) \cdot g\left(\boldsymbol{P}_{v}\right) \\
& \times\left[C_{S}\left\{\psi_{b} \cdot\left(\frac{\rho_{0}}{\rho_{m}}\right)^{1 / 2} \cdot \boldsymbol{P}_{m}^{1 / 2 \gamma_{u}}+\psi_{u}\right\}\right]
\end{aligned}
$$

This equation shows that a dimensionless factor, $S / V_{0}^{2 / 3}$, should be used instead of $S / V_{0}$, the vent ratio, since the former relies upon a rather sound theoretical basis. The term inside of [ ] in Eq. (10) involves the unknown variable, $\phi_{u}$, so that an assumption is made as follows. The calculated values of this term are plotted against $\psi_{u}$ in Fig. 1 where the parameter is $\boldsymbol{P}_{m}$, the dimensionless maximum pressure*. On the whole, the results are nearly equal to unity, so that we assume that the

* The calculated maximum pressures ${ }^{7)}$ for most combustible materials are in the range of 8 atm to 12 atm. 
Table 1

\begin{tabular}{|c|c|c|c|}
\hline Investigators & Dust material & $0^{2 / 3}$ (exp.) & $P_{v}[-]$ \\
\hline \multirow[t]{4}{*}{$\begin{array}{l}\text { Hartmann and } \\
\text { Nagy }^{3}\end{array}$} & $\begin{array}{l}\text { Cornstarch } \\
V_{0}=1 \mathrm{ft}^{3} \\
K_{G}=8461 \mathrm{~cm} \cdot \mathrm{atm} / \mathrm{sec}\end{array}$ & $\begin{array}{l}0.04 \\
0.05 \\
0.06 \\
0.08 \\
0.1 \\
0.12 \\
0.14\end{array}$ & $\begin{array}{l}1.755 \\
1.614 \\
1.59 \\
1.38 \\
1.26 \\
1.18 \\
1.12\end{array}$ \\
\hline & $\begin{array}{l}\text { Cellulose acetate } \\
V_{0}=1 \mathrm{ft}^{3} \\
K_{G}=5858.6 \mathrm{~cm} \cdot \mathrm{atm} / \mathrm{sec}\end{array}$ & $\begin{array}{l}0.04 \\
0.05 \\
0.06 \\
0.07 \\
0.09 \\
0.11\end{array}$ & $\begin{array}{l}1.826 \\
1.614 \\
1.444 \\
1.326 \\
1.17 \\
1.09\end{array}$ \\
\hline & $\begin{array}{l}\text { Pittsburgh coal } \\
V_{0}=1 \mathrm{ft}^{3} \\
K_{G}=3940.3 \mathrm{~cm} \cdot \mathrm{atm} / \mathrm{sec}\end{array}$ & $\begin{array}{l}0.02 \\
0.03 \\
0.04 \\
0.05 \\
0.06 \\
0.08\end{array}$ & $\begin{array}{l}2.321 \\
1.944 \\
1.519 \\
1.293 \\
1.16 \\
1.057\end{array}$ \\
\hline & $\begin{array}{l}\text { Pittsburgh coal } \\
V_{0}=64 \mathrm{ft}^{3} \\
K_{G}=3940.3 \mathrm{~cm} \cdot \mathrm{atm} / \mathrm{sec}\end{array}$ & $\begin{array}{l}0.03 \\
0.04 \\
0.06 \\
0.08 \\
0.1 \\
0.12 \\
0.16\end{array}$ & $\begin{array}{l}1.283 \\
1.217 \\
1.127 \\
1.076 \\
1.043 \\
1.025 \\
1.009\end{array}$ \\
\hline \multirow[t]{4}{*}{ Donat $^{2)}$} & $\begin{array}{l}\text { Coal } \\
V_{0}=1 \mathrm{~m}^{3} \\
K_{G}=83 \mathrm{~m} \cdot \mathrm{atm} / \mathrm{sec}\end{array}$ & $\begin{array}{l}0.05 \\
0.1 \\
0.2 \\
0.3\end{array}$ & $\begin{array}{l}2.0 \\
1.5 \\
1.3 \\
1.2\end{array}$ \\
\hline & $\begin{array}{l}\text { Organic Pigment } \\
V_{0}=1 \mathrm{~m}^{3} \\
K_{G}=286 \mathrm{~m} \cdot \mathrm{atm} / \mathrm{sec}\end{array}$ & $\begin{array}{l}0.05 \\
0.1 \\
0.2 \\
0.3\end{array}$ & $\begin{array}{l}4.4 \\
2.5 \\
1.5 \\
1.25\end{array}$ \\
\hline & $\begin{array}{l}\text { Organic Pigment } \\
V_{0}=30 \mathrm{~m}^{3} \\
K_{G}=286 \mathrm{~m} \cdot \mathrm{atm} / \mathrm{sec}\end{array}$ & $\begin{array}{l}0.1 \\
0.2 \\
0.3 \\
0.4\end{array}$ & $\begin{array}{l}2.7 \\
2.0 \\
1.6 \\
1.4\end{array}$ \\
\hline & $\begin{array}{l}\text { Aluminum } \\
V_{0}=1 \mathrm{~m}^{3} \\
K_{G}=606 \mathrm{~m} \cdot \mathrm{atm} / \mathrm{sec}\end{array}$ & $\begin{array}{l}0.05 \\
0.1 \\
0.2 \\
0.3\end{array}$ & $\begin{array}{l}6.5 \\
3.5 \\
2.2 \\
2.0\end{array}$ \\
\hline \multirow[t]{2}{*}{$\begin{array}{c}\text { Schwab and } \\
\text { Othmer }^{8)}\end{array}$} & $\begin{array}{l}\text { Tris.-2- } \\
\text { hydroxyethyl } \\
\text { isocynurate } \\
\text { (Finer than } 270 \text { mesh) } \\
V_{0}=1.3 \mathrm{l} \\
K_{G}=16.1 \mathrm{~m} \cdot \mathrm{atm} / \mathrm{sec}\end{array}$ & $\begin{array}{l}0.0046 \\
0.0057 \\
0.0075 \\
0.0103 \\
0.0164 \\
0.0205\end{array}$ & $\begin{array}{l}2.77 \\
2.33 \\
2.29 \\
1.75 \\
1.48 \\
1.14\end{array}$ \\
\hline & $\begin{array}{l}\text { PMMA } \\
\text { (Finer than } 270 \text { mesh) } \\
V_{0}=1.3 l \\
K_{G}=14.3 \mathrm{~m} \cdot \mathrm{atm} / \mathrm{sec}\end{array}$ & $\begin{array}{l}0.0046 \\
0.0057 \\
0.0075 \\
0.0103 \\
0.0164 \\
0.0205\end{array}$ & $\begin{array}{l}2.84 \\
2.70 \\
2.43 \\
1.95 \\
1.43 \\
1.27\end{array}$ \\
\hline
\end{tabular}

term inside of [ ] in Eq. (10) is unity. Then,

$$
\left(\frac{S}{V_{0}^{2 / 8}}\right)=\frac{P_{0}}{K_{G}}\left(\frac{g_{c} P_{c}}{\rho_{0}}\right)^{1 / 2} \cdot f\left(\gamma_{u}\right) \cdot g\left(\boldsymbol{P}_{v}\right)
$$

Therefore, from the values of $K_{G}$ for the dust in question and $P_{v}$, the pre-determined maximum pressure in direct relation to the strength of the plant, estimation of $S / V_{0}^{2 / 3}$ can be made by using Eq. (11).

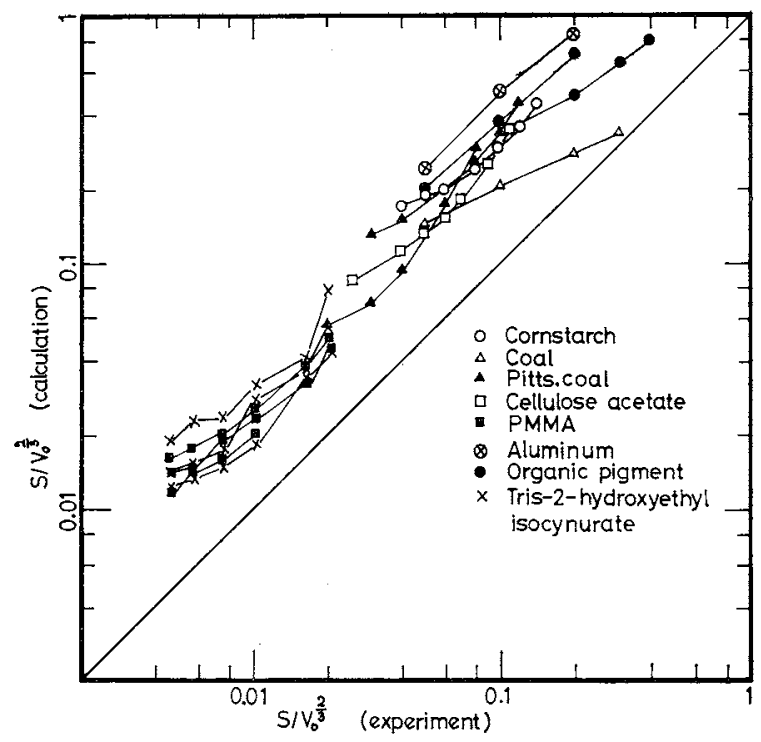

Fig. 2 Comparison of calculated $S / \boldsymbol{V}_{0}^{2 / 3}$ with experimental $S / \boldsymbol{V}_{0}{ }^{2 / 3}$

\section{Comparison of Predicted Values with Past Ex- perimental Data}

Much experimental work has been carried out with various scales of test apparatus as to vented explosions. The reported data for various kinds of dust materials are summarized in Table 1. On the other hand, values of $S / V_{0}^{2 / 3}$, calculated from Eq. (11), by use of the values of $P_{v}$ and $K_{G}$, are plotted in Fig. 2 against the corresponding experimental values of $S / V_{0}^{2 / 3}$. Although the calculated values are a little above the corresponding straight line on the whole, they agree fairly well with the experimental data not only in order of magnitude but also in the qualitative tendency of the straight line.

\section{Conclusions}

Although vented explosions of a dust cloud are very complicated phenomena, the authors have aimed at the theoretical evaluation of the vent area on the basis of the unsteady-state macroscopic energy balance and several assumptions. The derived results show that the relationship between vent area and vessel volume can be characterized by a dimensionless term which must be used for the scale-up factor instead of the conventional vent ratio. The calculated results based upon the theory are confirmed with past experimental data.

Since the most dangerous case has been taken into account, the calculated values of vent area are therefore a little greater than the experimental ones on the whole, but from the safety point of view, this treatment should be rather favourable in practice for the design purpose of protective installations.

Although not cited in this paper, the bursting 


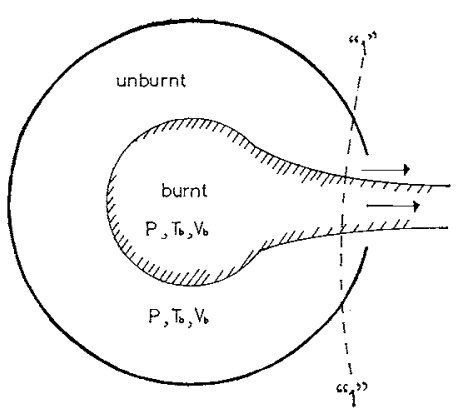

Fig. A-1 Conceptual model of explosion venting

pressure of the vent cover is of some importance in relation to the maximum pressure reached in a vented explosion, and a slight modification of the present theory is expected to include this bursting pressure in the correlation of $S / V_{0}^{2 / 3}$.

\section{Appendix A}

The unsteady-state macroscopic energy balance in a flow system can be represented as follows ${ }^{17}$ :

$$
\left.\frac{d}{d t}\left(U_{\mathrm{tot}}+K_{\mathrm{tot}}+\Phi_{\mathrm{tot}}\right)=-\Delta\left[\left(\hat{U}+P \hat{V}+\frac{1}{2} \bar{v} \bar{v}^{3}+\hat{\Phi}\right) w\right]+Q-W\right]
$$

Here $U_{\text {tot }}, K_{\text {tot }}$ and $\Phi_{\text {tot }}$ are respectively the total internal, kinetic, and potential energies in the system. $w$ is the mass rate of flow and the quantity $\hat{U}+P \hat{V}$ is called the enthalpy (per unit mass) which is given by the symbol $\hat{H}$. $Q$ is the thermal energy entering the system and $W$ is the work.

In the case of the vented explosion, a simplified conceptual diagram is shown in Fig. A-1. In this system the gas is considered to be divided into two parts, the burnt and the unburnt gas regions. No work is done in this system and the vessel is adiabatic, so that $W$ and $Q$ are zero. We assume that surface " 1 " in Fig. A-1 is near enough to the exit that essentially all of the gas is to its left side but far enough from the exit so that the gas velocity through surface " 1 " is negligible. For the region to the left of "1", Eq. (A-1) becomes

$$
\begin{aligned}
\frac{d}{d t}\left[M_{b} \cdot N_{b}\left(\hat{U}_{b}+\hat{\Phi}_{b}\right)+M_{u} \cdot N_{u}\left(\hat{U}_{u}+\hat{\Phi}_{u}\right)\right] & \\
= & \left(\hat{H}_{b}+\hat{\Phi}_{b}\right) M_{b} \frac{d N_{b}}{d t}+\left(\hat{H}_{u}+\hat{\Phi}_{u}\right) M_{u} \frac{d N_{u}}{d t}
\end{aligned}
$$

where the subscripts $b$ and $u$ denote burnt and unburnt, respectively. $M$ is the molecular weight of gas and $N$ is the number of moles of gas in the vessel at time $t . \quad N_{b}$ and $N_{\imath v}$ are represented as follows:

$$
\begin{aligned}
N_{b} & =\left(\frac{n_{b}}{M_{p}}+\frac{n_{0}}{M_{0}}\right) M(t)-\frac{1}{M_{b}} \int_{0}^{t} w_{b} d t \\
& =n_{c 0} M(t)-\frac{1}{M_{b}} \int_{0}^{t} w_{b} d t \\
N_{u} & =n_{0}\{1-\boldsymbol{M}(t)\}-\frac{1}{M_{u}} \int_{0}^{t} w_{u} d t
\end{aligned}
$$

where $n_{b}$ is the net increase of moles of gas evolved due to the combustion of one mole of particles, $M_{p}$, the molecular weight of particles and $n_{0}$ is the initial number of moles of air in the vessel. As to $\hat{\Phi}$ in Eq. (A-2), there are no external forces other than gravity in this system, so that $d \hat{\Phi} / d t=0$; then Eq. (A-2) becomes

$$
M_{b} \cdot N_{b} \frac{d \hat{U}_{b}}{d t}+M_{u} N_{u} \frac{d \hat{U}_{u}}{d t}=M_{b}\left(\hat{H}_{b}-\hat{U}_{b}\right) \frac{d N_{b}}{d t}+M_{u}\left(\hat{H}_{u}-\hat{U}_{u}\right) \frac{d N_{u}}{d t}
$$

Denoting the volume and the gas temperature of the burnt region at time $t$ as $V_{b}$ and $T_{b}$, and those of the unburnt region as $V_{u}$ and $T_{u}$, the equations of state of ideal gas are represented as follows:

$$
P V_{b}=N_{b} R T_{b}, \quad P V_{u}=N_{u} R T_{u}
$$

where $V_{b}+V_{u}=V_{0}$. From the adiabatic condition,

$$
\begin{aligned}
& \left(P / P_{\text {max }}\right)^{\left(1-\gamma_{b}\right) / \gamma_{b}=}=\left(T_{G 0} / T_{b}\right)
\end{aligned}
$$

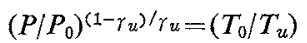

where $T_{G 0}$ is the maximum gas temperature of burnt region at $P=P_{\max }$. The relationship between the internal energy and the gas temperature gives

$$
d \hat{U}=\hat{C}_{v} d T
$$

where $\hat{C}_{v}$ is the specific heat of gas at constant volume. Substitution of Eqs. (A-6) and (A-8) in Eq. (A-5) gives

\begin{tabular}{|c|c|}
\hline$C_{S}$ & $=$ discharge coefficient \\
\hline$\hat{C}_{v}$ & $=$ specific heat of gas at constant volume $\left[\mathrm{cal} / \mathrm{g} \cdot{ }^{\circ} \mathrm{K}\right]$ \\
\hline$g_{c}$ & $=$ gravitational conversion factor $\left[\mathrm{g} \cdot \mathrm{cm} / \mathrm{Kg} \cdot \mathrm{sec}^{2}\right]$ \\
\hline$K_{G}$ & $=$ constant defined by Eq. (1) \\
\hline$K_{\text {tot }}$ & $=$ total kinetic energy in a system \\
\hline$M(t)$ & $=$ mass of particles burnt at time $t$ \\
\hline$M_{0}$ & $=$ maximal mass of particles burnt in a vessel \\
\hline$M_{b}$ & $=$ molecular weight of burnt gas \\
\hline$M_{p}$ & $=$ molecular weight of particle \\
\hline$M_{u}$ & $=$ molecular weight of unburnt gas \\
\hline$N_{b}$ & $=$ number of moles of burnt gas at time $t$ \\
\hline$N_{u}$ & $=$ number of moles of unburnt gas at time $t$ [mol] \\
\hline$n_{0}$ & $=$ initial number of moles of air in a vessel [mol] \\
\hline$\eta_{b}$ & $\begin{aligned}= & \text { net increase of moles of gas evolved due to } \\
& \text { the combustion of one mole of particles }\end{aligned}$ \\
\hline$n_{\ell 0}$ & $=$ defined in Eq. (A-3) \\
\hline$P$ & $=$ pressure in a vessel at time $t$ \\
\hline$P_{0}$ & $=$ initial pressure \\
\hline$P_{\max }$ & $=$ maximum pressure in a closed vessel \\
\hline$P_{v}$ & $\begin{array}{l}=\text { maximum pressure reached in a vented } \\
\text { vessel }\end{array}$ \\
\hline$Q$ & $=$ thermal energy \\
\hline$R$ & $=$ gas constant \\
\hline$S$ & $=$ area of vent \\
\hline$T_{0}$ & $=$ initial temperature of air \\
\hline$T_{b}$ & $=$ gas temperature of burnt region at time $t$ \\
\hline$T_{G 0}$ & $=$ maximum gas temperature in a closed vessel $\left[{ }^{\circ} \mathrm{K}\right]$ \\
\hline$T_{u}$ & $=$ gas temperature of unburnt region at time $t\left[{ }^{\circ} \mathrm{K}\right]$ \\
\hline & $=$ time variable \\
\hline$\hat{U}$ & $=$ internal energy per unit mass \\
\hline
\end{tabular}

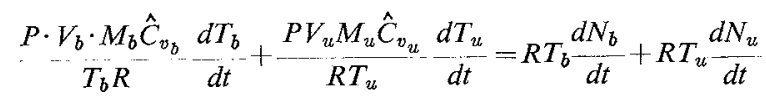

And further substitution of Eqs. (A-3), (A-4) and (A-7) in Eq. (A-9) gives

$$
\begin{gathered}
\left\{V_{b} \cdot\left(\frac{1}{\gamma_{b}}-\frac{1}{\gamma_{u}}\right)+\frac{V_{0}}{\gamma_{u}}\right\} \frac{d P}{d t}=V_{0}\left[P ^ { 1 - ( 1 / \gamma _ { b } ) } \cdot P _ { \operatorname { m a x } } ^ { 1 / \gamma _ { b } } \left\{\frac{d \boldsymbol{M}(t)}{d t}\right.\right. \\
\left.\left.-\frac{w_{b}}{n_{t 0} M_{b}}\right\}+P^{1-\left(1 / \gamma_{u}\right)} \cdot P_{0}^{1 / \gamma_{u}}\left\{-\frac{d \boldsymbol{M}(t)}{d t}-\frac{w_{u}}{n_{0} M_{u}}\right\}\right]
\end{gathered}
$$

Under the assumption that $\gamma_{b}$ nearly equals $\gamma_{u}$, Eq. (A-10) is reduced to Eq. (3).

\section{Nomenclature}




$\begin{array}{llr}U_{\text {tot }} & =\text { total internal energy at time } t & {[\mathrm{cal}]} \\ \hat{V} & =\text { volume per unit mass } & {\left[\mathrm{cm}^{3} / \mathrm{g}\right]} \\ V_{b} & =\text { volume of burnt region at time } t & {\left[\mathrm{~cm}^{3}\right]} \\ V_{u} & =\text { volume of unburnt region at time } t & {\left[\mathrm{~cm}^{3}\right]} \\ \bar{v} & =\text { average gas velocity } & {[\mathrm{cm} / \mathrm{sec}]} \\ W & =\text { work done in a system } & {[\mathrm{cal} / \mathrm{sec}]} \\ w_{b} & =\text { mass flow rate of burnt gas } & {[\mathrm{g} / \mathrm{sec}]} \\ w_{u} & =\text { mass flow rate of unburnt gas } & {[\mathrm{g} / \mathrm{sec}]} \\ \gamma_{b}, \gamma_{u} & =\text { ratios of specific heats of burnt and } \\ & & \\ \rho & =\text { denburnt gases } \\ \Phi & =\text { potential energy of gas per unit mass } & {\left[\mathrm{g} / \mathrm{cm}^{3}\right]} \\ \Phi_{\text {tot }} & =\text { total potential energy of gas in a vessel } & {[\mathrm{gal}]} \\ \psi_{b}, \psi_{u} & =\text { fractions of total vent area through which } \\ & & \text { the burnt and the unburnt gases are } \\ & \text { flowing out } & {[--]}\end{array}$

\title{
Literature Cited
}

1) Bird, R. B., W. E. Stewart, and E. N. Lightfoot: "Transport Phenomena", p. 456, John Wiley \& Sons, New York (1960).

2) Donat, C.: CEP technical manual, Loss Prevention, 11, 87 (1977).

3) Hartmann, I. and J. Nagy: Ind. Eng. Chem., 49, 1734 (1957).

4) Heinrich, H. J.: Chemie-Ing.-Tech., 38, 1125 (1966).

5) idem: VDI-Berichte, Nr. 165, 53 (1971).

6) Palmer, K. N.: Fire Research Note, No. 830, (1970).

7) Nomura, S. and T. Tanaka: Ind. Eng. Chem., Process Des. Dev. (in press).

8) Schwab, R.F. and D. F. Othmer: Chem. Proc. Engn., 165 (1964).

9) Yao, C.: CEP Technical Manual, Loss Prevention, 8, 1 (1974).

\section{FORMATION AND GROWTH OF NUCLEI BY SECONDARY NUCLEATION IN AGITATED SOLUTION OF K-ALUM}

\author{
HIDEJI YAMAMOTO AND YOSHIO HARANO \\ Department of Applied Chemistry, Osaka City \\ University, Osaka 558
}

\begin{abstract}
From the changes in light transmittance and electrical conductivity of a solution with elapsed time and from the size distribution of the final product crystals, the kinetics of the cited processes was studied. The experimental conditions are as follows: initial solute concentration, $C_{0}[\mathrm{~g}-\mathrm{mol} / l]$ $=0.22-0.38$; relative supersaturation ratio $\left(C / C_{s}\right)-1=S-1=0.01-0.33$; temperature $20-35^{\circ} \mathrm{C}$; agitation rate $630,1100 \mathrm{rpm}$; seed crystal, $1-10$ in number, size $325 \mu$. Over the ranges of $S-1=0.04-0.3$, the rates of growth and nucleation were given by the following equations: $d r / d t=$ $G=k_{g}(S-1)^{n}, \quad\left(n_{g}=1-1.4\right) \quad$ and $d N / d t=k_{n} N_{m}{ }^{2}(S-1)^{n} n=k_{n}{ }^{\prime} N_{m}{ }^{2} G(S-1)^{n_{n}}{ }^{\prime}, \quad\left(n_{n}=1.7-2.0\right.$, $\left.n_{n}{ }^{\prime}=0.6-0.7\right) . \quad N_{m}$ is the number of crystals with radius larger than $r_{\min }$, which is the radius of the smallest among the crystals breeding the secondary nuclei and which was estimated to be $100-120 \mu$. It is suggested that nucleation takes place due to collision among the crystals, and that the probability of the formed nuclei remaining able to grow depends on $(S-1)$.
\end{abstract}

\section{Introduction}

Despite many studies of secondary uncleation, little quaititative information has been obtained since secondary nucleation is a very complex phenomenon which takes place in the presence of parent crystals and under agitation or streaming of fluid.

The experimental methods hitherto applied to studies of secondary nucleation may be divided into three approaches. The first is to sample a given amount of

Received September 6,1979. Correspondence concerning this article should be addressed to Y. Harano. H. Yamamoto is now with Sakai Chem. Ind., Co., Sakai 590 . solution with elapsed time and to calculate the number of visible crystals to which the nuclei in the sample solution are grown separately ${ }^{1,11-13)}$. The second is to estimate the nucleation rate from the steady size distribution of suspended crystals in a continuous well-stirred tank crystallizer (MSMPR). Since its proposal by Randolph et al. ${ }^{8)}$, this method has been widely applied to studies of seconđary nucleation ${ }^{6,10,14)}$. The rate thus estimated gives valuable information for practical purposes, but does not express the true nature of secondary nucleation. The third is to estimate the nucleation rate analytically from changes of solute concentration and surface or sectional area of suspend- 